\title{
Direct Effect of Chenodeoxycholic Acid on Differentiation of Mouse Embryonic Stem Cells Cultured under Feeder-Free Culture Conditions
}

\author{
Soon-Jung Park, ${ }^{1,2}$ Seul-Bi Lee, ${ }^{1,2}$ Dong-Sup Lee, ${ }^{3}$ Young-Joon Ryu, ${ }^{4}$ \\ Gene Lee, ${ }^{1,2}$ and Jaejin Cho ${ }^{1,2}$ \\ ${ }^{1}$ Lab of Developmental Biology and Stem Cell Differentiation/Transplantation, School of Dentistry, Seoul National University, \\ 28 Yongun-dong, Chongno-gu, Seoul 110-749, Republic of Korea \\ ${ }^{2}$ Dental Research Institute, School of Dentistry, Seoul National University, 28 Yongun-dong, Chongno-gu, \\ Seoul 110-749, Republic of Korea \\ ${ }^{3}$ Department of Biomedical Sciences, College of Medicine, Seoul National University, 28 Yongun-dong, Chongno-gu, \\ Seoul 110-799, Republic of Korea \\ ${ }^{4}$ Department of Pathology, College of Medicine, University of Ulsan and Asan Medical Center, 88 Olympic-ro 43-gil, Songpa-gu, \\ Seoul 138-736, Republic of Korea \\ Correspondence should be addressed to Jaejin Cho; jcho@snu.ac.kr
}

Received 9 August 2012; Revised 18 October 2012; Accepted 21 October 2012

Academic Editor: Irma Virant-Klun

Copyright (C) 2013 Soon-Jung Park et al. This is an open access article distributed under the Creative Commons Attribution License, which permits unrestricted use, distribution, and reproduction in any medium, provided the original work is properly cited.

Chenodeoxycholic acid (CDCA), a farnesoid X receptor (FXR) ligand, is a member of the nuclear receptor family and is probably involved in regulating the cellular activities of embryonic stem (ES) cells. Recently, although it was reported that the FXR ligand can mediate differentiation, apoptosis, and/or growth arrest in several cell types, it is still not well known how CDCA mediates effects in ES cells. Therefore, we investigated the direct effect of CDCA on $\mathrm{mES}$ cells. Feeder-free mES cells were treated in a dose-dependent manner with CDCA $(50,100$, and $200 \mu \mathrm{M})$ for $72 \mathrm{~h}$, and then a $100 \mu \mathrm{M}$ CDCA treatment was performed for an additional $72 \mathrm{~h}$. We analyzed the morphology, cell growth, cell characteristics, immunocytochemistry, and RT-PCR. In CDCA-treated cells, we observed the disappearance of pluripotent stem cell markers including alkaline phosphatase, Oct4, and Nanog and a time- and dose-dependent increase in expression of nestin, PAX6, and $\alpha$-smooth muscle actin, but not $\alpha$-fetoprotein. The $100 \mu \mathrm{M}$ CDCAtreated cells in their second passage continued this differentiation pattern similar to those in the controls. In conclusion, these results suggest that CDCA can guide mES cells by an FXR-independent pathway to differentiate into ectoderm and/or mesoderm, but not endoderm.

\section{Introduction}

Since the establishment of embryonic stem (ES) cell lines $[1,2]$, it has been known that ES cells have the capacity for self-renewal and pluripotency, with the ability to differentiate into multiple cell types in vitro and in vivo. These characteristics of ES cells make them a valuable model system for differentiation study and cell-based regeneration therapies.

Numerous reports have documented the differentiation of ES cells into specific cell types, such as neurons [3], cardiomyocytes [4], adipocytes [5], endothelial cells [6], hepatocytes [7], keratinocytes [8], and pancreatic cells [9] under the appropriate culture conditions. So far, ES cell differentiation required the formation of an embryoid body (EB) in most studies in general. However, alternative approaches have shown directed differentiation of ES cells into a desired lineage without going through EB formation $[10,11]$. There are some problems in ES cell differentiation through EB formation. It may lead to uncontrollable complexity and to unwanted cell types [12], and some of the cells of the EB might not be terminally differentiated [10].

The farnesoid X receptor (FXR, NR1H4), meanwhile, may modulate the differentiation into myocyte [13] during myogenesis of tissue-specific stem cells. Therefore, the 
differentiated cell population tends to be directed more uniform, and a larger number of precursors and more differentiated cells can be obtained using this pathway. The FXR, a member of the nuclear receptor superfamily, is highly expressed in liver, intestine, and kidney tissues [14]. FXR is known to be a key player in the control of multiple metabolic pathways including bile acid biosynthesis from cholesterol and lipid/glucose metabolism $[15,16]$. In liver, especially, activated FXR induces liver regeneration by a homeostatic mechanism [17] and affects vascular remodeling [18]. In the intestine, it protects the tissue from bacterialinduced mucosal injury by bile acids [19]. It is also known that the FXR activators inhibit cell proliferation, trigger differentiation, and induce apoptosis. Bile acids reduce the growth of keratinocytes, human fibroblasts, and smooth muscle cells [20-22]. Additionally, activated FXR plays a critical role in regulating adipogenesis [23] and also induces apoptosis in cancer cells [24]. However, studies on the effects of activated FXR on proliferation or differentiation of ES cells are scarce.

Chenodeoxycholic acid (CDCA, $3 \alpha, 7 \alpha$-dihydroxy-5 $\beta$ cholanic acid) is a primary bile acid directly synthesized from cholesterol. It was shown to be the most potent activator of the FXR $[25,26]$. It binds directly to FXR, which then regulates several known FXR target genes and induces bile acid-binding protein for bile acid transport [27]. Therefore, CDCA is not simply metabolic products but also regulates involving gene transcription and signaling of transduction pathway. Moreover, CDCA is involved in many cellular activities including cell proliferation, differentiation, and apoptosis $[23,28]$.

In this paper, we investigated the effects of the FXR ligand and CDCA on the differentiation of mouse ES (mES) cells without a feeder layer or EB formation. To examine whether CDCA mediates differentiation through FXR signaling, we checked the mRNA expression of FXR in CDCA-induced and differentiated mES cells. Additionally, direct differentiation was performed in the presence of LIF in order to determine the relationship between LIF signaling and CDCA-mediated cellular activities.

\section{Materials and Methods}

2.1. Mouse ES Cell Cultures. The E14TG2a (ATCC number CRL-1821) mouse ES (mES) cell line was routinely cultured on feeder layers of primary mouse embryonic fibroblasts (MEF) pretreated with mitomycin C. The cells were maintained with Dulbecco's modified Eagle's medium (DMEM; Welgene, Daegu, Republic of Korea) supplemented with 15\% fetal bovine serum (FBS; HyClone Laboratories, Logan, UT, USA), $0.1 \mathrm{mM}$ 2-mercaptoethanol (Sigma-Aldrich Corp, St. Louis, MO, USA), 1\% nonessential amino acids (NEAA; Gibco-Invitrogen, Carlsbad, CA, USA), 1\% (v/v) penicillinstreptomycin (Gibco-Invitrogen), and 1,000 U/mL of recombinant mouse leukemia inhibitory factor (LIF; Chemicon, Temecula, CA, USA) in $5 \% \mathrm{CO}_{2}$ at $37^{\circ} \mathrm{C}$. The mES cells were subcultured onto new feeders every 3 or 4 days using $0.05 \%$ trypsin-EDTA (Gibco-Invitrogen).
2.2. Treatment of mES Cells with Chenodeoxycholic Acid (CDCA). For direct differentiation of mES cells by CDCA, feeder cells were removed by plating on nongelatin coated dish for $1 \mathrm{~h}$, which allowed the feeder cells to adhere, while most of the mES cells stayed in the suspension. The suspended mES cells were once transferred onto a new $0.1 \%$ gelatin-coated dish for propagation in the presence of $1,000 \mathrm{U} / \mathrm{mL}$ of LIF. The feeder-free mES cells were subcultured after $24 \mathrm{~h}$. Then the cells were incubated under different conditions for $72 \mathrm{~h}$. The cells were incubated in (i) basal medium (spontaneously differentiated control), (ii) basal medium supplemented with 1,000 U/mL of LIF (undifferentiated control), and (iii) basal medium supplemented with $0.1 \%$ dimethyl sulfoxide (DMSO; Sigma-Aldrich Corp) in the absence of LIF (solvent control). Treated groups were cultured in basal medium supplemented with (iv) $50 \mu \mathrm{M}$, (v) $100 \mu \mathrm{M}$, and (vi) $200 \mu \mathrm{M}$ of CDCA. After the treatment for $72 \mathrm{~h}$, the control groups and $100 \mu \mathrm{M}$ CDCA-treated cells were subcultured using $0.05 \%$ trypsin-EDTA (Gibco-Invitrogen) on new gelatinized dishes and treated with $100 \mu \mathrm{M}$ CDCA for additional $72 \mathrm{~h}$.

The cells were incubated in basal medium, basal medium supplemented with $1,000 \mathrm{U} / \mathrm{mL}$ of LIF, and basal medium supplemented with $0.1 \%$ dimethyl sulfoxide (DMSO; SigmaAldrich) as a control. Treated groups were cultured in basal medium supplemented with 50,100 , and $200 \mu \mathrm{M}$ of chenodeoxycholic acid (CDCA, Sigma-Aldrich) for $72 \mathrm{~h}$. Then, the $100 \mu \mathrm{M}$ CDCA-treated cells were subcultured and treated with $100 \mu \mathrm{M}$ CDCA for an additional $72 \mathrm{~h}$. The cell number was counted by trypan blue dye exclusion. The experiment was repeated three times.

2.3. Cell Viability Assay. Cell viability was assessed by a tetrazolium salt (WST-1)-based colorimetric assay. A commercial WST-1 kit (EZ CyToX; Daeil Lab, Seoul, Republic of Korea) was used. The absorbance was measured at $450 \mathrm{~nm}$ Bio-Rad microplate reader Model-550 (Bio-Rad, Hercules, CA, USA).

2.4. Alkaline Phosphatase Activity. The cells were fixed with a $4 \%$ paraformaldehyde solution and stained with Naphthol/Fast Red Violet Solution (Mix Fast Red Violet (FRV) with Naphthol AS-BI phosphate solution and water in a $2: 1: 1$ ratio) at room temperature in the dark for $15 \mathrm{~min}$. Later, the cells were rinsed with PBS and observed under a phase contrast microscope.

2.5. Immunocytochemistry. To detect pluripotent stem cell markers and three-germ layer-specific marker antigens, the cells were fixed in culture dishes with $4 \%$ paraformaldehyde in phosphate-buffered saline (PBS) $(0.01 \mathrm{M}, \mathrm{pH} 7.4)$ for $15 \mathrm{~min}$. Endogenous peroxidase activity was blocked by hydrogen peroxide for $30 \mathrm{~min}$ at RT after a PBS wash. The cells were permeabilized with $0.1 \%$ Triton X-100 for $10 \mathrm{~min}$ and incubated with normal goat serum (Jackson Immunoresearch Laboratory, West Grove, PA) for $60 \mathrm{~min}$ to block nonspecific binding sites. The cells were incubated with the primary antibodies overnight at $4^{\circ} \mathrm{C}$. The primary antibodies were Oct4 (Santa Cruz Biotechnology, Santa Cruz, 
TABle 1: Primer sequences and cycling conditions used for RT-PCR.

\begin{tabular}{|c|c|c|c|}
\hline Gene & Primer sequence & Annealing temperature & Product size \\
\hline \multirow{2}{*}{ Oct 4} & Forward $5^{\prime}$-GAAGCCCTCCCTACAGCAGA-3' & \multirow{2}{*}{$60^{\circ} \mathrm{C}$} & \multirow{2}{*}{$297 \mathrm{bp}$} \\
\hline & Reverse $5^{\prime}$-CAGAGCAGTGACGGGAACAG-3' & & \\
\hline \multirow{2}{*}{ Nanog } & Forward $5^{\prime}$-CCCCACAAGCCTTGGAATTA-3' & \multirow{2}{*}{$60^{\circ} \mathrm{C}$} & \multirow{2}{*}{$255 \mathrm{bp}$} \\
\hline & Reverse $5^{\prime}$-CTCAAATCCCAGCAACCACA- $3^{\prime}$ & & \\
\hline \multirow{2}{*}{ Nestin } & Forward $5^{\prime}$-TAGAGGTGCAGCAGCTGCAG-3' & \multirow{2}{*}{$60^{\circ} \mathrm{C}$} & \multirow{2}{*}{$170 \mathrm{bp}$} \\
\hline & Reverse 5' -AGCGATCTGACTCTGTAGAC-3' & & \\
\hline \multirow{2}{*}{ NCAM } & Forward $5^{\prime}$-AGATGGTCAGTTGCTGCCAA- $3^{\prime}$ & \multirow{2}{*}{$60^{\circ} \mathrm{C}$} & \multirow{2}{*}{$187 \mathrm{bp}$} \\
\hline & Reverse $5^{\prime}$-AGAAGACGGTGTGTCTGCTT-3' & & \\
\hline \multirow{2}{*}{$\alpha$-SMA } & Forward $5^{\prime}$-ACTGGGACGACATGGAAAAG-3' & \multirow{2}{*}{$60^{\circ} \mathrm{C}$} & \multirow{2}{*}{$240 \mathrm{bp}$} \\
\hline & Reverse $5^{\prime}$-CATCTCCAGAGTCCAGCACA-3' & & \\
\hline \multirow{2}{*}{ Desmin } & Forward $5^{\prime}$-TGACAACCTGATAGACGACC- $3^{\prime}$ & \multirow{2}{*}{$60^{\circ} \mathrm{C}$} & \multirow{2}{*}{$180 \mathrm{bp}$} \\
\hline & Reverse $5^{\prime}$-TTAAGGAACGCGATCTCCTC- $3^{\prime}$ & & \\
\hline \multirow{2}{*}{$\alpha$-FP } & Forward $5^{\prime}$-TGCACGAAAATGAGTTTGGGA-3' & \multirow{2}{*}{$60^{\circ} \mathrm{C}$} & \multirow{2}{*}{$159 \mathrm{bp}$} \\
\hline & Reverse $5^{\prime}$-TTGCAGCCAACACATCGCTA- $3^{\prime}$ & & \\
\hline \multirow{2}{*}{ Albumin } & Forward $5^{\prime}$-TGCTGCTGATTTTGTTGAGG-3' & \multirow{2}{*}{$60^{\circ} \mathrm{C}$} & \multirow{2}{*}{$500 \mathrm{bp}$} \\
\hline & Reverse $5^{\prime}$-GCTCACTCACTGGGGTCTTC-3' & & \\
\hline \multirow{2}{*}{ FXR } & Forward $5^{\prime}$-TTGCGACAAGTGACCTCCAC-3' & \multirow{2}{*}{$58^{\circ} \mathrm{C}$} & \multirow{2}{*}{$653 \mathrm{bp}$} \\
\hline & Reverse $5^{\prime}$-TGATGGTTGAATGTCCGGAG-3' & & \\
\hline \multirow{2}{*}{ GAPDH } & Forward 5' -GTCATCATACTTGGCAGGTT-3' & \multirow{2}{*}{$60^{\circ} \mathrm{C}$} & \multirow{2}{*}{$489 \mathrm{bp}$} \\
\hline & Reverse $5^{\prime}$-GTCGTGGAGTCTACTGGTGT-3' & & \\
\hline
\end{tabular}

NCAM: neural cell adhesion molecule; $\alpha$-SMA: alpha-smooth muscle actin; $\alpha$-FP: alpha-fetoprotein; FXR: farnesoid X receptor; GAPDH: glyceraldehyde-3phosphate dehydrogenase.

CA, USA) and Nanog (Abcam, UK) as pluripotent stem cell markers, nestin (Chemicon) and PAX6 (Chemicon) as ectoderm markers, $\alpha$-smooth muscle actin (Sigma-Aldrich) as mesoderm marker, and $\alpha$-fetoprotein (Santa Cruz) as endoderm marker. The cells were then probed with secondary antibodies (peroxidase-labeled goat anti-mouse IgG or goat anti-rabbit IgG (1:200); Jackson Immunoresearch Laboratory) for $1 \mathrm{~h}$ at RT. DAB (DAKO, Carpinteria, CA, USA) was used for visualization about 30 seconds.

2.6. Total RNA Isolation and RT-PCR. Total RNA was extracted from the cells using TRIzol (Gibco-Invitrogen) according to the manufacturer's instructions. After total RNA extraction, the cells were treated with DNAse I (Rnase free, Takara, Japan) for discarding genomic DNA contamination. The concentration and quality of isolated RNA were determined using an ND-1000 Spectrophotometer (NanoDrop Technologies, USA). Complementary DNA was synthesized from $1 \mu \mathrm{g}$ of total RNA using M-MLV Reverse Transcriptase Kit I (Bioneer, Daejon, Republic of Korea) with oligo-dT primers. One microliter of cDNA was used as template in the PCR reactions. Each PCR reaction mixture contained PCR buffer (2.0 mM MgCl 2$), 2.5 \mathrm{mM}$ of each dNTP, $10 \mathrm{pM}$ of each mouse-specific primer sets, one unit of i-MAX II DNA Polymerase (Intron, Seoul, Republic of Korea).The primer sets and the PCR conditions are summarized in Table 1. The PCR products were analyzed by electrophoresis on a $1.5 \%$ agarose gel containing $0.4 \mu \mathrm{g} / \mathrm{mL}$ ethidium bromide (SigmaAldrich Corp). Band intensities were quantified three times each by densitometry analysis using Bio1D software (Vilber Lourmat, Mame la Vallee, France).

\section{Results}

3.1. Morphological Changes and Viability of CDCA-Treated $m E S$ Cells. The attached feeder-free mES cells formed tightly packed colonies, same as cells on feeder layers. The nucleus shows irregularly shaped thin smooth nuclear membrane with prominent multiple nucleoli. The cytoplasm is scanty in volume and cytoplasmic molding in shape. Feeder-free mES cells still showed the characteristics of pluripotent stem cells, in terms of their alkaline phosphatase activity, Oct4, and Nanog expression (see Supplement 1 in Supplementary Material available online at doi:http://dx.doi.org/10.1155/2013/375076). This result indicates that mES cells can be maintained in an undifferentiated state in feeder-free culture conditions.

When LIF was discarded, the mES cells differentiated spontaneously. Moreover, the CDCA-treated cells showed remarkable changes. The differentiated cells showed decrease in nucleus size, abundant cytoplasm, and low nucleus/cytoplasm ratio, in a dose- and time-dependent manner. The prominent nucleoli are also decreased in size, and cytoplasmic pod extension was noted. We observed primarily this type of cells in the $50 \mu \mathrm{M}$ CDCA-treated group and more stretched sharp-ended cytoplasmic cells in the $100 \mu \mathrm{M}$ CDCA-treated group (Supplement 2). CDCA-treated cells became larger, flatter, and more elongated in a timedependent manner. The high-dose CDCA-treated $(200 \mu \mathrm{M})$ 

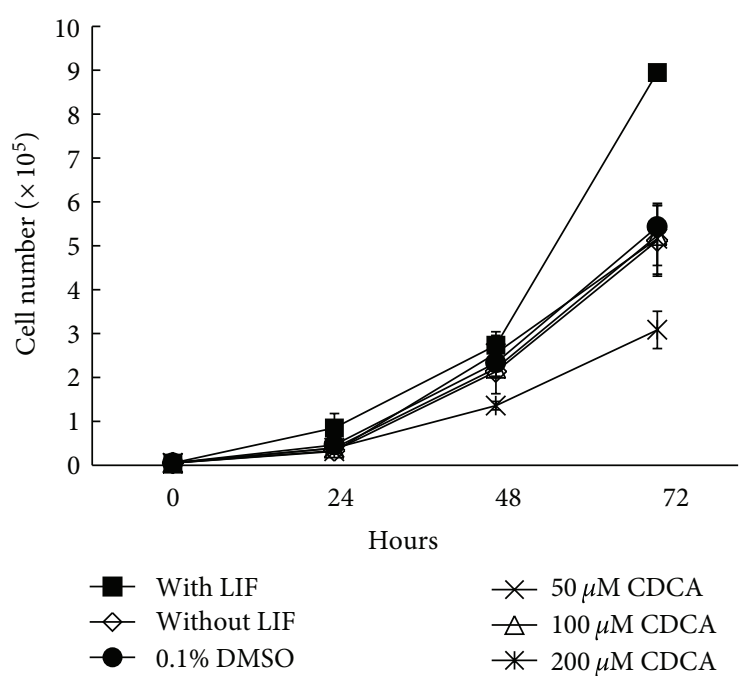

(a)

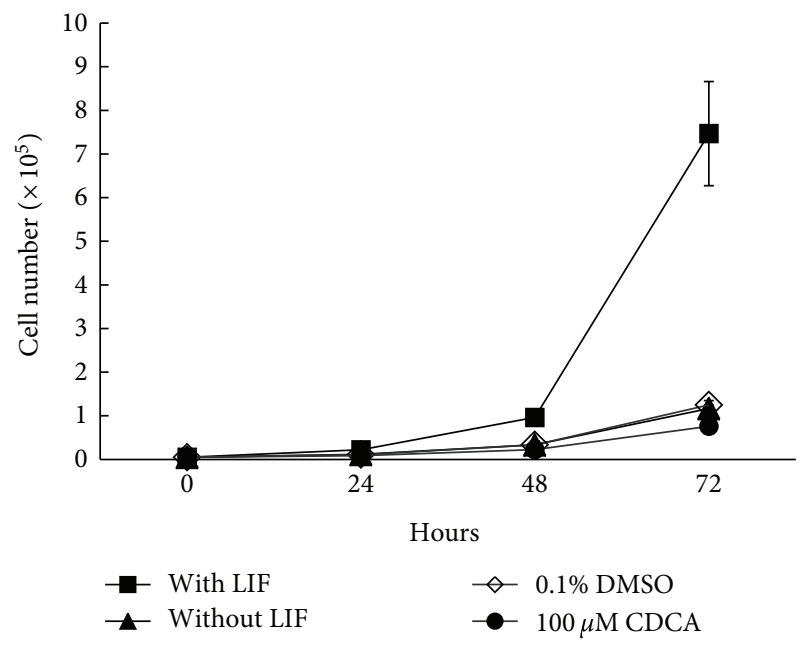

(b)

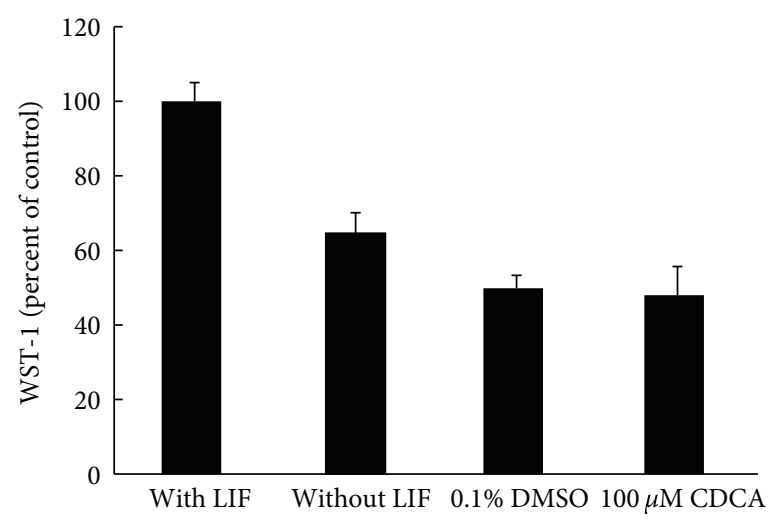

(c)

FIGURE 1: Growth rate and cell viability of CDCA-treated mES cells. Changes in mES cell number after CDCA treatment (a) and after the second round of treatment with $100 \mu \mathrm{M}$ CDCA (b). The effects of $100 \mu \mathrm{M}$ CDCA on the viability of subcultured mES cells after $72 \mathrm{~h}$ incubation, measured by the WST-1 assay. Data represent viability as a percentage of the control (1000 U/mL of LIF-treated cells) (c). Data are expressed as the mean \pm SE $(n=3)$. LIF: leukemia inhibitory factor; DMSO: dimethyl sulfoxide; CDCA: chenodeoxycholic acid.

group shows abundant and thin cytoplasm with vacuolation, similar to the senescence phenomenon. Furthermore, the treated cells had inhibited cell proliferation and the cell number was decreased by $43.25 \%$ compared to the vehicle control (Figure 1(a)).

After subculturing, the mES cells treated with $100 \mu \mathrm{M}$ CDCA changed their morphology according to the previously described pattern. Treatment with $100 \mu \mathrm{M}$ CDCA reduced the cell number to the cell number seen in the negative controls (without LIF and 0.1\% DMSO-treated group) compared to the positive control with LIF (Figure $1(\mathrm{~b}))$. The cell viability of $100 \mu \mathrm{M}$ CDCA-treated cells, as measured by MTT assay, was similar to that of the negative controls. These results indicate that $100 \mu \mathrm{M}$ CDCA does not have a cytotoxic effect on mES cells grown under feeder-free conditions, even after a 2 nd passage. In addition, adding LIF to the medium clearly stimulates the mES cells under feederfree conditions (Figure 1(c)).
3.2. Characterization of CDCA-Treated mES Cells. The expression of ALP, Oct4, and Nanog was lower in LIFwithdrawn mES cells and DMSO-treated cells than in LIFtreated mES cells. CDCA treatment reduced the expression of ALP, Oct4, and Nanog in a concentration-dependent manner, even when compared to negative controls. ALP, Oct4, and Nanog expression in LIF control showed almost $100 \%$ positive cells. CDCA decreased the ALP expression about $3-5 \%$ positive cells. These phenomena were similar to Nanog expression. In contrast, decrease of Oct 4 expression by CDCA was much slower than ALP and Nanog. $50 \mu \mathrm{M}$ CDCA reduced Oct4-positive cells by $70 \%$ compared to LIF control. The decreasing effect showed CDCA dose-dependent manner $(100 \mu \mathrm{M}$ : $50 \%, 200 \mu \mathrm{M}: 20 \%)$. Oct4 positive cells almost disappeared but still remained at the second passage of mES cells treated by $100 \mu \mathrm{M}$ CDCA, respectively, (Figure $2)$. While the cells in the control groups were negative for all three germ layer markers, CDCA-treated mES cells 
LIF

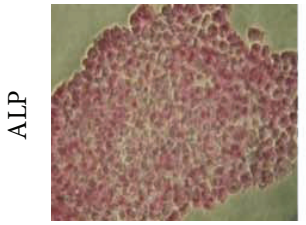

(a)

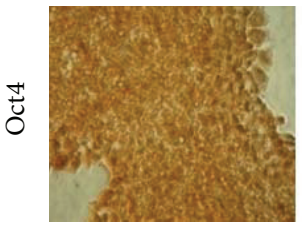

(b)

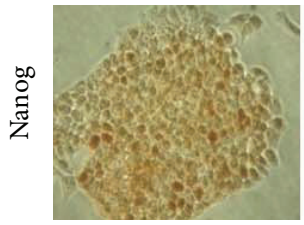

(c)
$0.1 \%$ DMSO

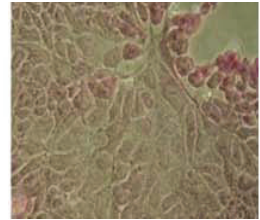

(d)

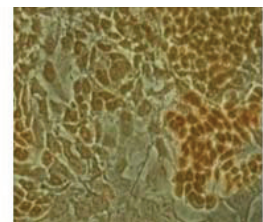

(e)

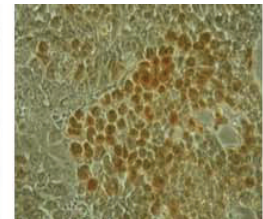

(f)
50

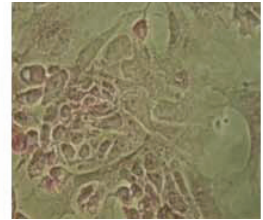

(g)

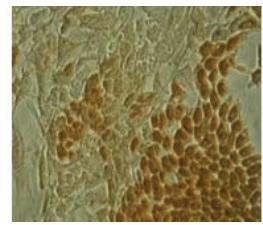

(h)

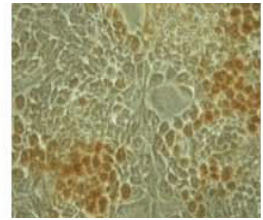

(i)
100

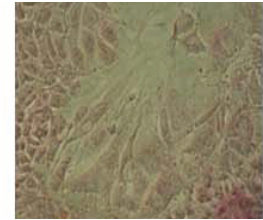

(j)

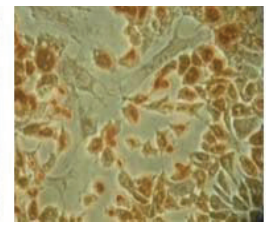

(k)

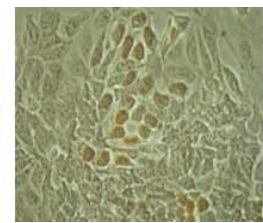

(l)
200

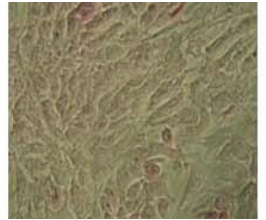

(m)

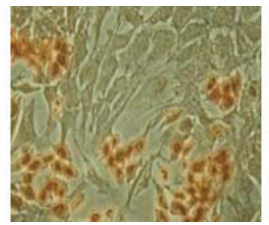

(n)

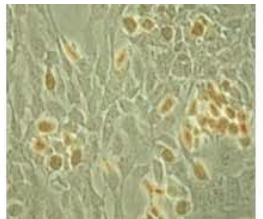

(o) 100-2nd

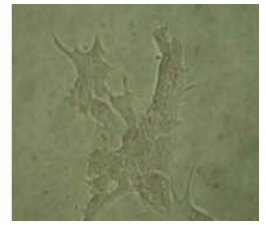

(p)

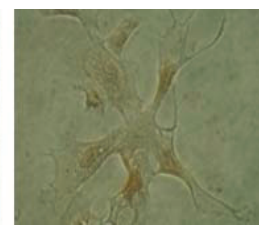

(q)

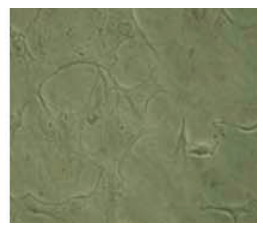

(r) $\overline{50 \mu \mathrm{m}}$

FIGURE 2: Changes of pluripoent markers in CDCA-treated mES cells. mES cells were cultivated with $50 \mu \mathrm{M}, 100 \mu \mathrm{M}$, or $200 \mu \mathrm{M}$ CDCA for $72 \mathrm{~h}$. Subcultured mES cells were treated with $100 \mu \mathrm{M}$ CDCA for another $72 \mathrm{~h}$. The cells were probed with antibodies against pluripotent stem cell markers, alkaline phosphatase (ALP), Oct4, and Nanog. LIF: leukemia inhibitory factor; DMSO: dimethyl sulfoxide; CDCA: chenodeoxycholic acid

showed strong expression of nestin and $\alpha$-smooth muscle actin. CDCA increased nestin expression in concentrationdependent manner $(50 \mu \mathrm{M}: 20 \%, 100 \mu \mathrm{M}: 50 \%, 200 \mu \mathrm{M}$ : $70 \%)$. The second passage of $100 \mu \mathrm{M}$ CDCA showed almost 90\% cells showing positive. CDCA increased Pax6 expression, but the pattern was much slower than nestin. At the second passage of $100 \mu \mathrm{M}$ CDCA-treated mES cells showed positive cells by $50 \%$, respectively. Subcultured mES cells were treated with $100 \mu \mathrm{M}$ CDCA for another $72 \mathrm{~h}$. CDCA induced the $\alpha$-smooth muscle actin expression in lower concentration compared to nestin and Pax6. From $50 \mu \mathrm{M}$ CDCA treatment, it showed strong expression. However, $\alpha$ fetoprotein was not detected in any CDCA-treated groups (Figure 3).

The mRNA expression pattern was similar to the protein expression pattern. In the $200 \mu \mathrm{M}$ CDCA-treated mES cells cultured for $72 \mathrm{~h}$, Oct $4 \mathrm{mRNA}$ expression was downregulated and the phenomenon disappeared at $100 \mu \mathrm{M}$ CDCA for the second passage (total $144 \mathrm{~h}$ incubation with CDCA). Nanog mRNA expression was maintained at a steady state, but it disappeared similar to Oct 4 at $100 \mu \mathrm{M}$ CDCA for the second passage. Cells treated with CDCA for $72 \mathrm{~h}$ expressed nestin, NCAM, $\alpha$-smooth muscle actin, and desmin at $200 \mu \mathrm{M}$ CDCA. The pattern was clearer at $100 \mu \mathrm{M}$ CDCA for the second passage. However, $\alpha$-fetoprotein and albumin were not expressed, which is consistent with the results of the immunocytochemical analysis (Figures 4(a) and 4(b)). FXR
mRNA was not detected in any CDCA-treated cells or control group cells (Supplement 3).

\section{Discussion}

In this study, we investigated the effect of CDCA, an FXR ligand, on mES cell differentiation under feeder-free conditions. We focused on the effect of CDCA on the proliferation and differentiation of mES cells into specific lineages by analyzing the changes in mES cell characteristics, mRNA expression patterns, and cell physiology. First, we treated mES cells cultured without a feeder layer with different doses of CDCA in the culture medium for $72 \mathrm{~h}$. Because $100 \mu \mathrm{M}$ CDCA showed an effect on the differentiation of mES cells without changing cell viability, when compared to the controls, we treated the cells for an additional $72 \mathrm{~h}$. The second round treatment of mES cells with CDCA resulted in ectodermal and mesodermal differentiation, but not endodermal lineage. During differentiation, the cell viability was similar to that observed for the negative controls ( $0.1 \%$ DMSO without LIF).

In our preliminary experiments, we changed the $\mathrm{mES}$ cell culture to feeder-free culture by adding 1,000 IU LIF. The cells were successfully maintained, but the margin of the colony was occasionally irregular. All of the ES cell characteristics were maintained, as previously reported elsewhere [29].

Since the regulation of the nuclear receptor, and especially FXR-dependent bile acid signaling, could contribute 
LIF

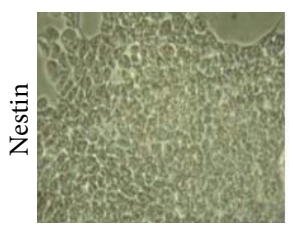

(a)

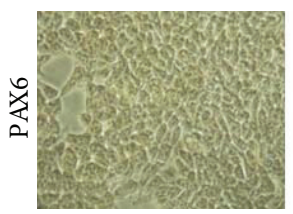

(b)

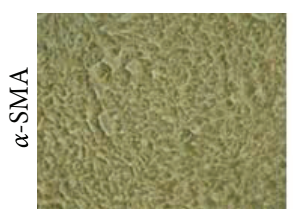

(c)

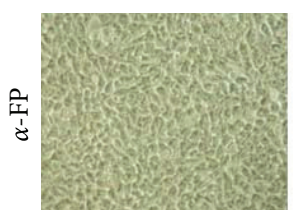

(d)
$0.1 \% \mathrm{DMSO}$

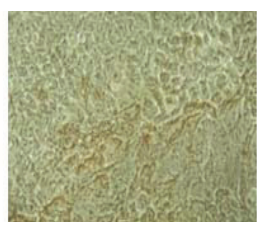

(e)

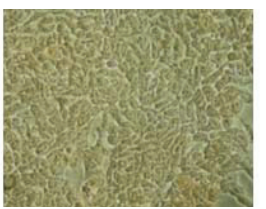

(f)

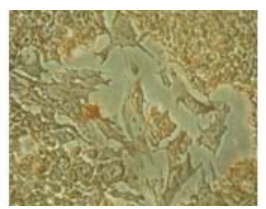

(g)

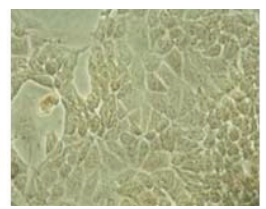

(h)
50

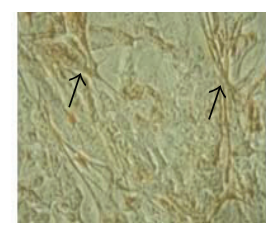

(i)

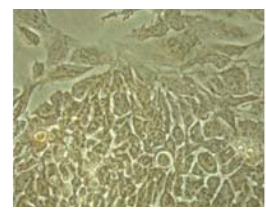

(j)

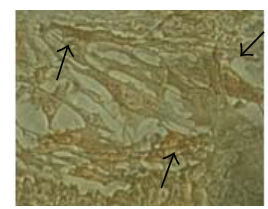

(k)

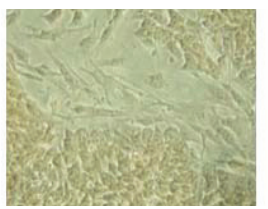

(1)
100

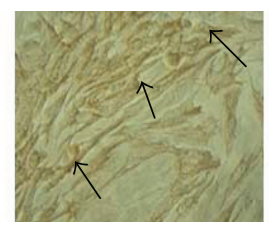

(m)

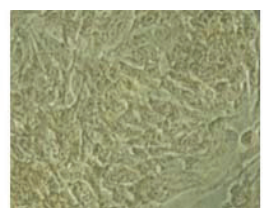

(n)

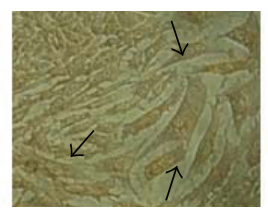

(o)

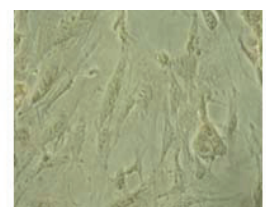

(p)
200

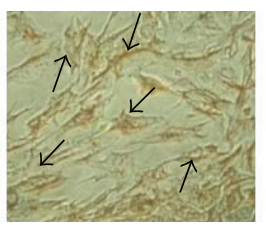

(q)

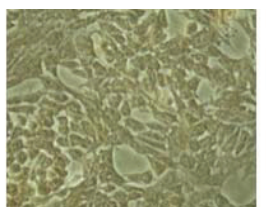

(r)

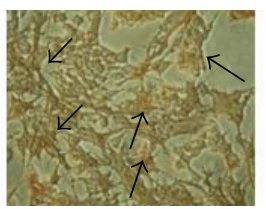

(s)

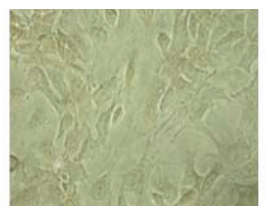

(t) 100-2nd

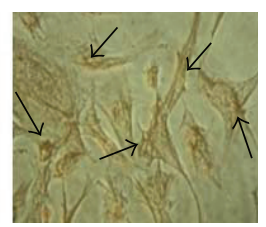

(u)

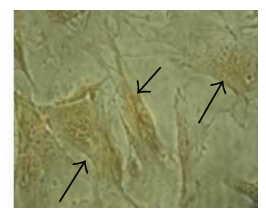

(v)

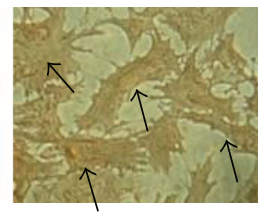

(w)

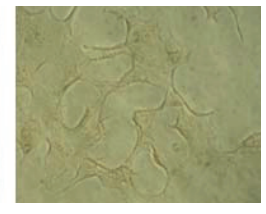

(x) $\overline{50 \mu \mathrm{m}}$

FIGURE 3: Characteristic changes in CDCA-treated mES cells. mES cells were cultivated with $50 \mu \mathrm{M}, 100 \mu \mathrm{M}$, or $200 \mu \mathrm{M}$ CDCA for $72 \mathrm{~h}$. Subcultured mES cells were treated with $100 \mu \mathrm{M}$ CDCA for another $72 \mathrm{~h}$. Lineage-specific markers such as nestin and PAX6, $\alpha$-smooth muscle actin ( $\alpha$-SMA), and $\alpha$-fetoprotein $(\alpha$-FP). LIF: leukemia inhibitory factor; DMSO: dimethyl sulfoxide; CDCA: chenodeoxycholic acid.

to endodermal organ and liver regeneration [17], there is a possibility that the FXR ligand, CDCA, could cause differentiation of $\mathrm{mES}$ cells. However, the direct differentiation of mES cells by treatment with CDCA without an EB step has not yet been studied. To determine the optimal concentration of CDCA for inducing differentiation of mES cells, we used 50, 100, and $200 \mathrm{uM} \mathrm{CDCA}$ to treat the mES cells for $72 \mathrm{~h}$. In $\mathrm{mES}$ cells treated with 100 and $200 \mu \mathrm{M}$ CDCA, the pluripotent signals were reduced as the cells differentiated into ectodermal and mesodermal lineages. Concomitant results were shown for mRNA expression analysis by RT-PCR, demonstrating that CDCA can induce the differentiation of $\mathrm{mES}$ cells. However, endodermal differentiation was not observed. Since $200 \mu \mathrm{M}$ CDCA reduced the cell number as well as viability about $50 \%$ than $100 \mu \mathrm{M}$ CDCA, we chose to use a $100 \mu \mathrm{M}$ dose for the second passage. In the second round of treatment, differentiation of mES cells into ectodermal and endodermal lineages was more significant. The expression of pluripotent markers of ES cells such ALP, Oct4, and Nanog was almost absent at the protein level, and the mRNA levels of these markers were drastically reduced, while maintaining the cell viability.
Our results indicate that CDCA treatment of undifferentiated mES cells causes differentiation by a pathway other than the one involved in adult organ regeneration and does not involve the FXR receptor. CDCA is a primary bile acid synthesized directly from cholesterol in the liver and secreted via the bile into the small intestine that plays a key role in the digestion and absorption of dietary fats [30]. CDCA-activated FXR regulates expression of genes whose products are critically important for bile acid and cholesterol homeostasis in cultivated hepatocytes [31,32] and liver slices [33]. Moreover, several studies have shown that the FXR ligand, CDCA, can induce differentiation, inhibit proliferation, and induce the apoptosis of several primary cell types including human fibroblast [21] and keratinocytes [20]. Furthermore, CDCA can regulate the differentiation of mouse preadipocytes into mature adipocytes [23] and can mediate apoptosis in vascular smooth muscle cells and breast cancer cells $[22,24]$.

It is not reported whether there is an endogenous expression in embryonic stage but there are several reports that human fetus in early gestation (weeks 13-19) produces CDCA [34] and porcine fetus also does in even earlier stage 


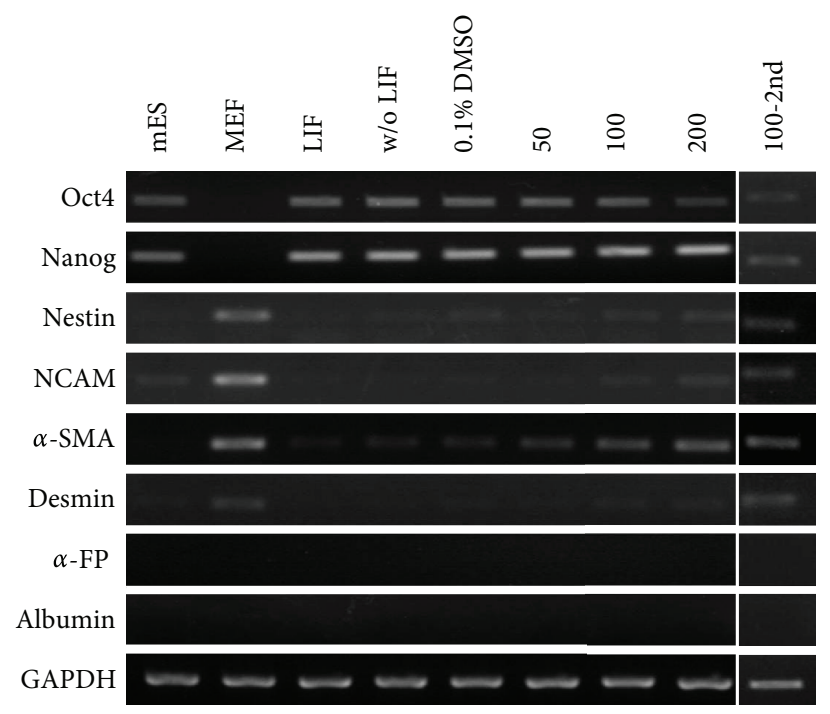

(a)
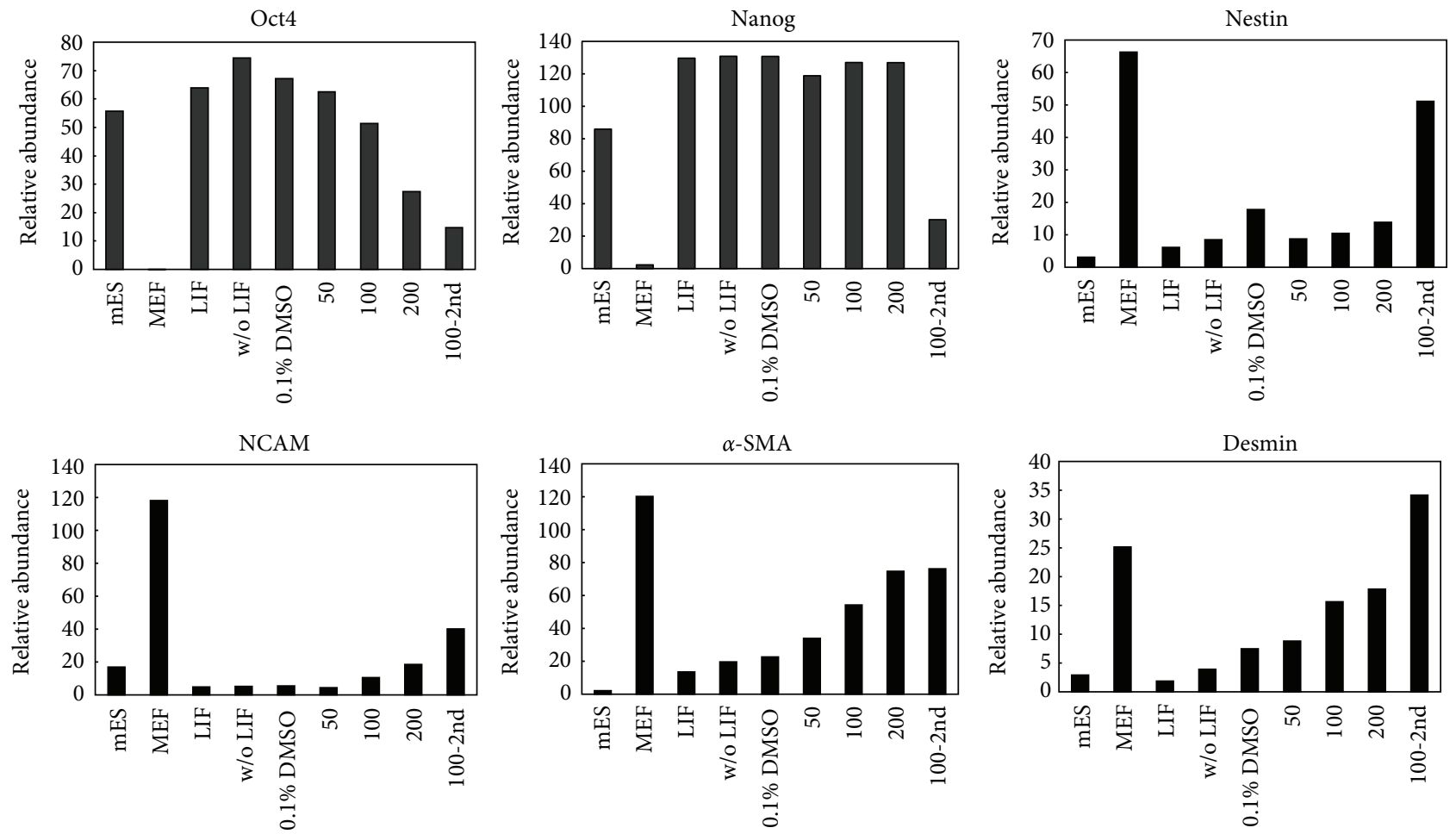

(b)

FIGURE 4: Characterization of CDCA-treated mES cells by RT-PCR analysis. (a) The mRNA expression of pluripotent stem cell markers and lineage specific makers were analyzed. The mES cells were cultivated with $50 \mu \mathrm{M}, 100 \mu \mathrm{M}$, or $200 \mu \mathrm{M}$ CDCA for $72 \mathrm{~h}$. Sub-cultured mES cells were treated with $100 \mu \mathrm{M}$ CDCA for another $72 \mathrm{~h}$. MEF, mouse embryonic fibroblast, LIF, leukemia inhibitory factor; DMSO, dimethyl sulfoxide; CDCA, chenodeoxycholic acid. (b) Relative semi-quantitation of PCR signals by image analysis.

during gestation (weeks 4) [35]. Recently, FXR-deficient mice showed that FXR may control adipocyte differentiation via PPAR- $\gamma$ and $\mathrm{Wnt} / \beta$-catenin pathways [36].

There have been several reports that CDCA can mediate effects in an FXR-independent regulatory manner. CDCA can mediate the activity of PKC $[37,38]$, which plays a key role in the regulation of cell growth, differentiation, and apoptosis [39]. Moreover, CDCA can directly activate the growth regulatory gene, cyclooxygenase-2 [40], and transcription factors such as c-Fos [41] and activator protein-1 (AP1) [42], which are involved in the regulation of cell growth and differentiation. Recent reports suggest that bile acidmediated apoptosis is dependent on death receptor signaling [43] or mitochondria dysfunction [44]. Through activation of 
these diverse signaling pathways, CDCA can regulate several cellular activities.

Although the exact mechanism of CDCA-induced differentiation of mES cells has to be elucidated, we have demonstrated that CDCA directly induces the differentiation of mES cells into ectodermal and mesodermal cells in a dosedependent manner but does not promote endodermal differentiation. It would be also necessary to investigate the CDCAinduced differentiation for longer period to prove determination of their lineages to the ectodermal/mesodermal not endodermal cells in the near future.

Furthermore, CDCA-induced differentiation of $\mathrm{mES}$ cells seems to be mediated by an FXR-independent mechanism. In conclusion, these results provide useful information concerning the role of CDCA in the cellular activities of mES cells. However, determination of the exact mechanisms of CDCA-mediated antiproliferation and differentiation of mES cells requires further research.

\section{Acknowledgment}

This research was supported by the Bio \& Medical Technology Development Program of the National Research Foundation (NRF) funded by the Korean government (MEST) (no. 2011-0027827).

\section{References}

[1] M. J. Evans and M. H. Kaufman, "Establishment in culture of pluripotential cells from mouse embryos," Nature, vol. 292, no. 5819, pp. 154-156, 1981.

[2] J. A. Thomson, J. Itskovitz-Eldor, S. S. Shapiro et al., "Embryonic stem cell lines derived from human blastocysts," Science, vol. 282, no. 5391, pp. 1145-1147, 1998.

[3] R. Martín-Ibáñez, N. Urbán, S. Sergent-Tanguy et al., "Interplay of leukemia inhibitory factor and retinoic acid on neural differentiation of mouse embryonic stem cells," Journal of Neuroscience Research, vol. 85, no. 12, pp. 2686-2701, 2007.

[4] L. Ding, X. Liang, D. Zhu, and Y. Lou, "Peroxisome proliferatoractivated receptor $\alpha$ is involved in cardiomyocyte differentiation of murine embryonic stem cells in vitro," Cell Biology International, vol. 31, no. 9, pp. 1002-1009, 2007.

[5] T. L. Chen, W. J. Shen, X. W. Qiu, T. Li, A. R. Hoffman, and F. B. Kraemer, "Generation of novel adipocyte monolayer cultures from embryonic stem cells," Stem Cells and Development, vol. 16, no. 3, pp. 371-380, 2007.

[6] M. Festag, C. Sehner, P. Steinberg, and B. Viertel, "An in vitro embryotoxicity assay based on the disturbance of the differentiation of murine embryonic stem cells into endothelial cells. I: establishment of the differentiation protocol," Toxicology in Vitro, vol. 21, no. 8, pp. 1619-1630, 2007.

[7] J. Heo, V. M. Factor, T. Uren et al., "Hepatic precursors derived from murine embryonic stem cells contribute to regeneration of injured liver," Hepatology, vol. 44, no. 6, pp. 1478-1486, 2006.

[8] I. Haase, R. Knaup, M. Wartenberg, H. Sauer, J. Hescheler, and G. Mahrle, "In vitro differentiation of murine embryonic stem cells into keratinocyte-like cells," European Journal of Cell Biology, vol. 86, no. 11-12, pp. 801-805, 2007.

[9] M. Nakanishi, T. S. Hamazaki, S. Komazaki, H. Okochi, and M. Asashima, "Pancreatic tissue formation from murine embryonic stem cells in vitro," Differentiation, vol. 75, no. 1, pp. 1-11, 2007.

[10] T. Teratani, H. Yamamoto, K. Aoyagi et al., "Direct hepatic fate specification from mouse embryonic stem cells," Hepatology, vol. 41, no. 4, pp. 836-846, 2005.

[11] D. C. Hay, D. Zhao, A. Ross, R. Mandalam, J. Lebkowski, and W. Cui, "Direct differentiation of human embryonic stem cells to hepatocyte-like cells exhibiting functional activities," Cloning and Stem Cells, vol. 9, no. 1, pp. 51-62, 2007.

[12] X. Xu, B. Kahan, A. Forgianni et al., "Endoderm and pancreatic islet lineage differentiation from human embryonic stem cells," Cloning and Stem Cells, vol. 8, no. 2, pp. 96-107, 2006.

[13] M. Dubé, M. E. Huot, and E. W. Khandjian, "Muscle specific fragile $\mathrm{X}$ related protein 1 isoforms are sequestered in the nucleus of undifferentiated myoblast," BMC Genetics, vol. 1, no. 1, article 4, 2000.

[14] Y. Zhang, H. R. Kast-Woelbern, and P. A. Edwards, "Natural structural variants of the nuclear receptor farnesoid X receptor affect transcriptional activation," The Journal of Biological Chemistry, vol. 278, no. 1, pp. 104-110, 2003.

[15] G. Lambert, M. J. A. Amar, G. Guo, H. B. Brewer, F. J. Gonzalez, and C. J. Sinal, "The farnesoid X-receptor is an essential regulator of cholesterol homeostasis," The Journal of Biological Chemistry, vol. 278, no. 4, pp. 2563-2570, 2003.

[16] K. Ma, P. K. Saha, L. Chan, and D. D. Moore, "Farnesoid $\mathrm{X}$ receptor is essential for normal glucose homeostasis," The Journal of Clinical Investigation, vol. 116, no. 4, pp. 1102-1109, 2006.

[17] W. Huang, K. Ma, J. Zhang et al., "Nuclear receptor-dependent bile acid signaling is required for normal liver regeneration," Science, vol. 312, no. 5771, pp. 233-236, 2006.

[18] A. Das, M. E. Fernandez-Zapico, S. Cao et al., "Disruption of an SP2/KLF6 repression complex by SHP is required for farnesoid $\mathrm{X}$ receptor-induced endothelial cell migration," The Journal of Biological Chemistry, vol. 281, no. 51, pp. 39105-39113, 2006.

[19] T. Inagaki, A. Moschetta, Y. K. Lee et al., "Regulation of antibacterial defense in the small intestine by the nuclear bile acid receptor," Proceedings of the National Academy of Sciences of the United States of America, vol. 103, no. 10, pp. 3920-3925, 2006.

[20] D. A. Vessey, K. H. Lee, and E. Lau, "Effect of bile acids on the growth and differentiation of cultured human keratinocytes," Skin Pharmacology, vol. 10, no. 5-6, pp. 265-274, 1997.

[21] K. Ramaesh, F. A. Billson, and M. C. Madigan, "Effect of bile acids on fibroblast proliferation and viability," Eye, vol. 12, part 4, pp. 717-722, 1998.

[22] D. Bishop-Bailey, D. T. Walsh, and T. D. Warner, "Expression and activation of the farnesoid X receptor in the vasculature," Proceedings of the National Academy of Sciences of the United States of America, vol. 101, no. 10, pp. 3668-3673, 2004.

[23] G. Rizzo, M. Disante, A. Mencarelli et al., "The farnesoid $\mathrm{X}$ receptor promotes adipocyte differentiation and regulates adipose cell function in vivo," Molecular Pharmacology, vol. 70, no. 4 , pp. 1164-1173, 2006.

[24] K. E. Swales, M. Korbonits, R. Carpenter, D. T. Walsh, T. D. Warner, and D. Bishop-Bailey, "The farnesoid X receptor is expressed in breast cancer and regulates apoptosis and aromatase expression," Cancer Research, vol. 66, no. 20, pp. 10120-10126, 2006. 
[25] D. J. Parks, S. G. Blanchard, R. K. Bledsoe et al., "Bile acids: natural ligands for an orphan nuclear receptor," Science, vol. 284, no. 5418, pp. 1365-1368, 1999.

[26] J. L. Lew, A. Zhao, J. Yu et al., “The farnesoid X receptor controls gene expression in a ligand- and promoter-selective fashion," The Journal of Biological Chemistry, vol. 279, no. 10, pp. 8856-8861, 2004.

[27] M. Makishima, A. Y. Okamoto, J. J. Repa et al., "Identification of a nuclear receptor for bite acids," Science, vol. 284, no. 5418, pp. 1362-1365, 1999.

[28] A. A. Powell, J. M. LaRue, A. K. Batta, and J. D. Martinez, "Bile acid hydrophobicity is correlated with induction of apoptosis and/or growth arrest in HCT116 cells," Biochemical Journal, vol. 356, no. 2, pp. 481-486, 2001.

[29] Y. H. Loh, Q. Wu, J. L. Chew et al., "The Oct4 and Nanog transcription network regulates pluripotency in mouse embryonic stem cells," Nature Genetics, vol. 38, no. 4, pp. 431-440, 2006.

[30] T. Claudel, B. Staels, and F. Kuipers, "The farnesoid X receptor: a molecular link between bile acid and lipid and glucose metabolism," Arteriosclerosis, Thrombosis, and Vascular Biology, vol. 25, no. 10, pp. 2020-2030, 2005.

[31] L. Malerød, M. Sporstøl, L. K. Juvet et al., "Bile acids reduce SRBI expression in hepatocytes by a pathway involving FXR/RXR, SHP, and LRH-1," Biochemical and Biophysical Research Communications, vol. 336, no. 4, pp. 1096-1105, 2005.

[32] A. K. Peyer, D. Jung, M. Beer et al., "Regulation of human liver $\delta$-aminolevulinic acid synthase by bile acids," Hepatology, vol. 46, no. 6, pp. 1960-1970, 2007.

[33] D. Jung, M. G. L. Elferink, F. Stellaard, and G. M. M. Groothuis, "Analysis of bile acid-induced regulation of FXR target genes in human liver slices," Liver International, vol. 27, no. 1, pp. 137-144, 2007.

[34] M. Nakagawa and K. D. R. Setchell, "Bile acid metabolism in early life: studies of amniotic fluid," Journal of Lipid Research, vol. 31, no. 6, pp. 1089-1098, 1990.

[35] T. Kuramoto, J. Miyamoto, M. Konishi, T. Hoshita, T. Masul, and M. Une, "Bile acids in porcine fetal bile," Biological and Pharmaceutical Bulletin, vol. 23, no. 10, pp. 1143-1146, 2000.

[36] M. Abdelkarim, S. Caron, C. Duhem et al., "The farnesoid X receptor regulates adipocyte differentiation and function by promoting peroxisome proliferator-activated receptor- $\gamma$ and interfering with the Wnt/ $\beta$-catenin pathways," The Journal of Biological Chemistry, vol. 285, no. 47, pp. 36759-36767, 2010.

[37] C. Branting, R. Toftgard, I. P. Hallstrom, and J. Rafter, "Role of protein kinase $\mathrm{C}$ in growth stimulation of primary mouse colonic epithelial cells," In Vitro Cellular \& Developmental Biology, vol. 31, no. 10, pp. 790-795, 1995.

[38] A. Zimber, A. Chedeville, J. P. Abita, V. Barbu, and C. Gespach, "Functional interactions between bile acids, all-trans retinoic acid, and 1,25-dihydroxy-vitamin D3 on monocytic differentiation and myeloblastin gene down-regulation in HL60 and THP-1 human leukemia cells," Cancer Research, vol. 60, no. 3, pp. 672-678, 2000.

[39] G. C. Blobe, L. M. Obeid, and Y. A. Hannun, "Regulation of protein kinase $\mathrm{C}$ and role in cancer biology," Cancer and Metastasis Reviews, vol. 13, no. 3-4, pp. 411-431, 1994.

[40] F. Zhang, K. Subbaramaiah, N. Altorki, and A. J. Dannenberg, "Dihydroxy bile acids activate the transcription of cyclooxygenase-2," The Journal of Biological Chemistry, vol. 273, no. 4, pp. 2424-2428, 1998.
[41] R. Di Toro, G. Campana, G. Murari, and S. Spampinato, "Effects of specific bile acids on c-fos messenger RNA levels in human colon carcinoma Caco-2 cells," European Journal of Pharmaceutical Sciences, vol. 11, no. 4, pp. 291-298, 2000.

[42] D. Qiao, W. Chen, E. D. Stratagoules, and J. D. Martinez, "Bile acid-induced activation of activator protein-1 requires both extracellular signal-regulated kinase and protein kinase $\mathrm{C}$ signaling," The Journal of Biological Chemistry, vol. 275, no. 20, pp. 15090-15098, 2000.

[43] H. Higuchi and G. J. Gores, "Bile acid regulation of hepatic physiology IV. Bile acids and death receptors," American Journal of Physiology, vol. 284, no. 5, pp. G734-G738, 2003.

[44] K. Schlottmann, P. F. Wachs, C. R. Krieg, F. Kullmann, J. Scholmerich, and G. Rogler, "Characterization of bile saltinduced apoptosis in colon cancer cell lines," Cancer Research, vol. 60, no. 15, pp. 4270-4276, 2000. 

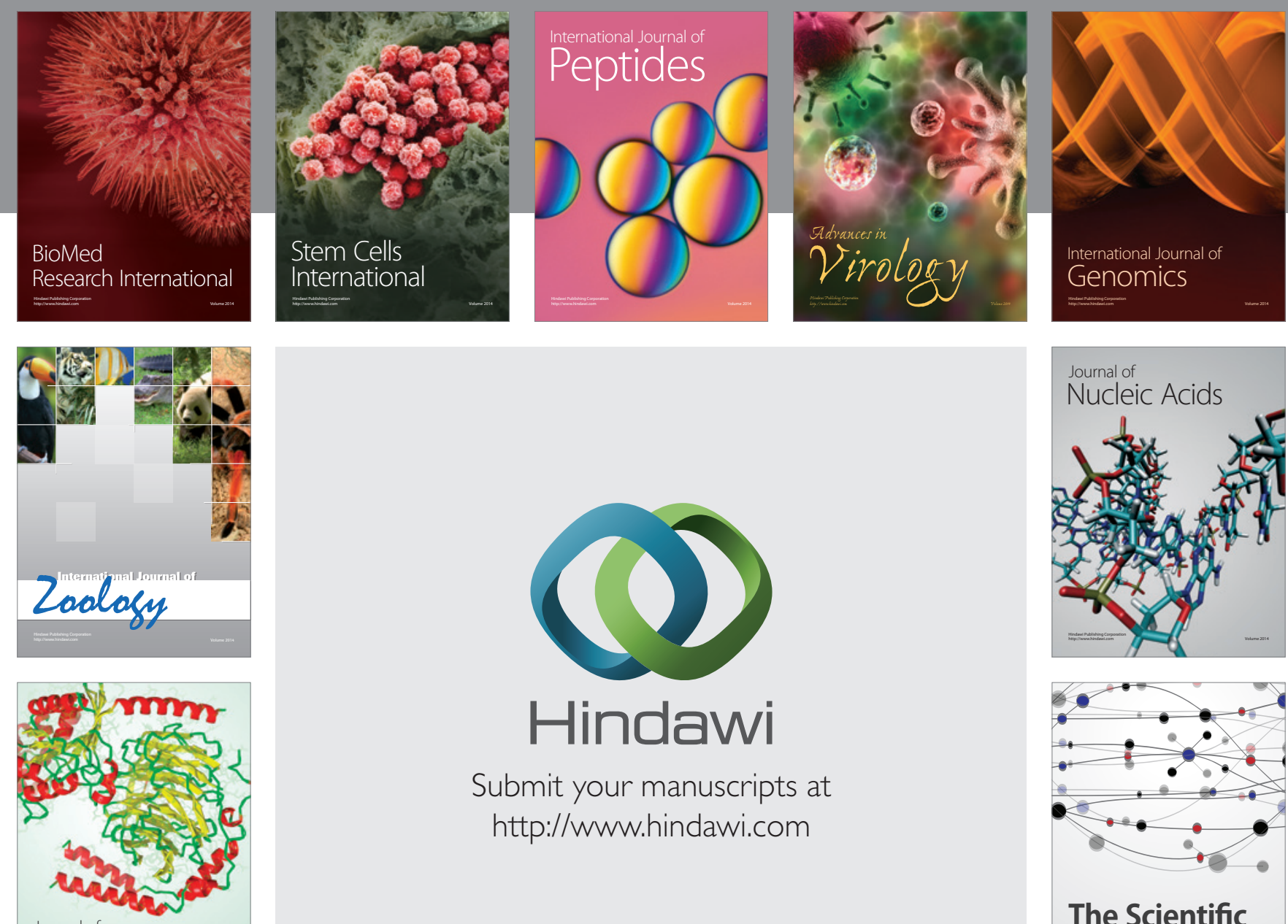

Submit your manuscripts at

http://www.hindawi.com

Journal of
Signal Transduction
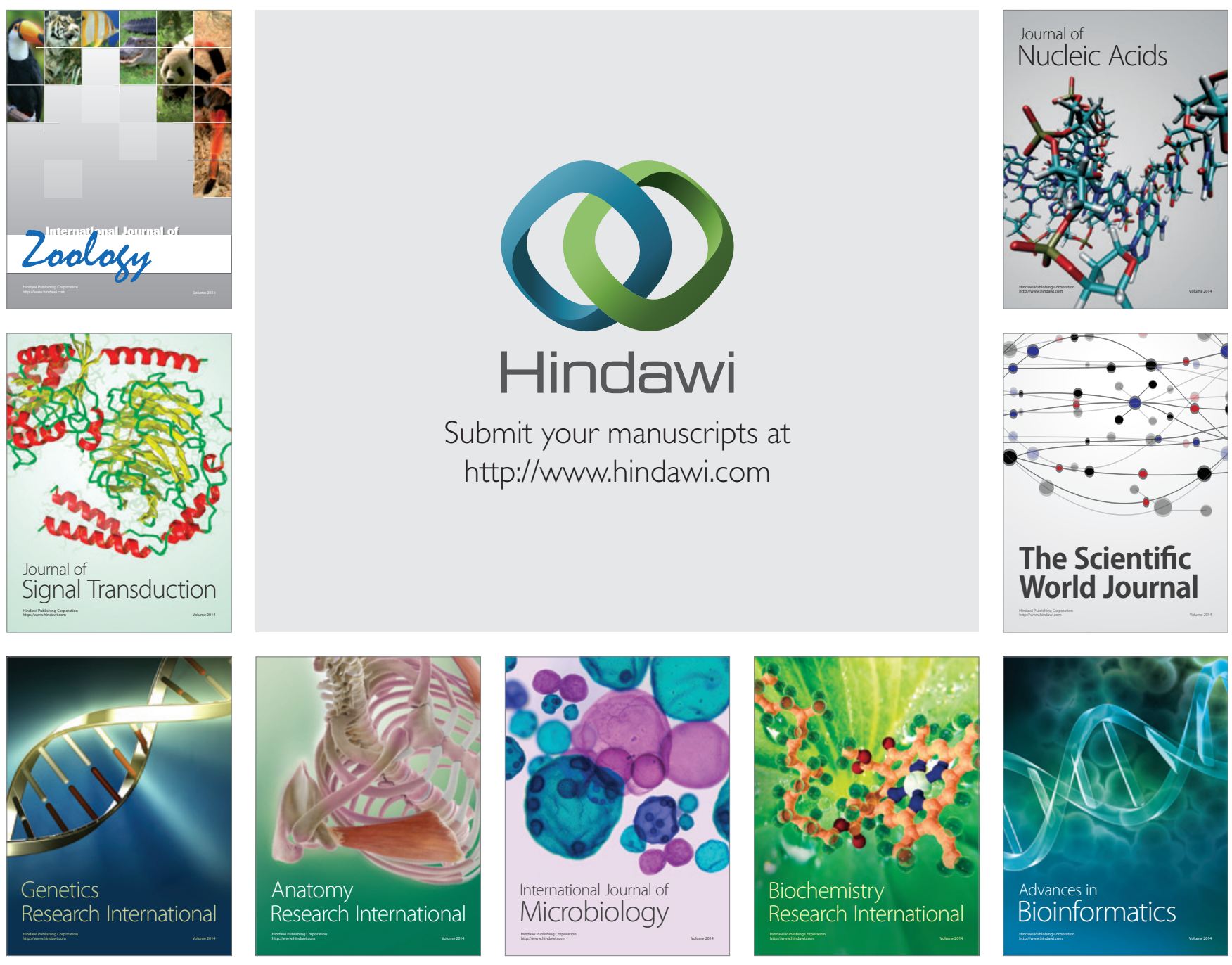

The Scientific World Journal
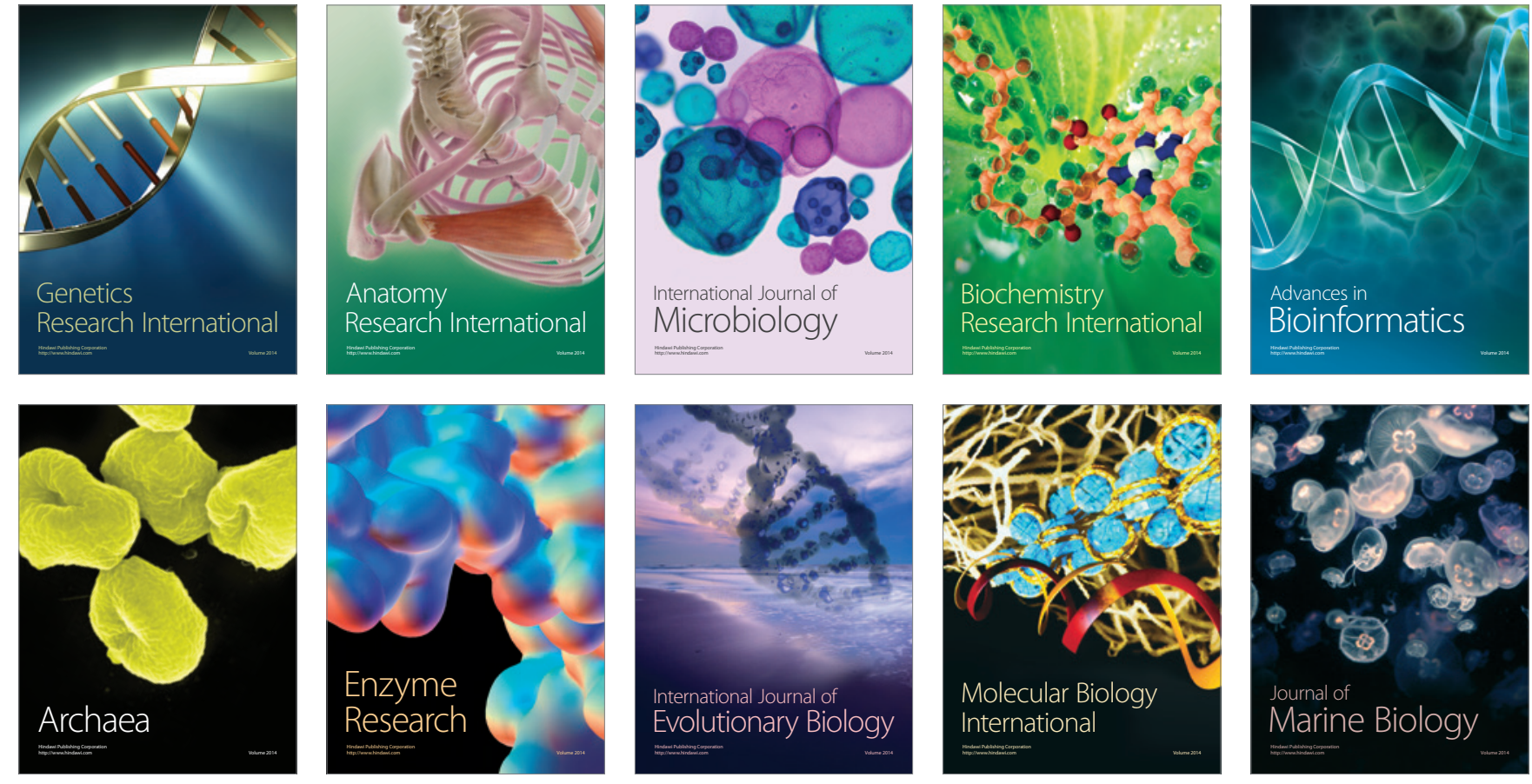